\title{
Identifying the Functions of Code Switching in Computer Mediated Online Communication
}

\author{
Areej Dawoud \\ English Language Institute \\ King Abdul-Aziz University, Jeddah, Saudi Arabia \\ E-mail: adawoud@kau.edu.sa \\ Sayyed Rashid Shah (Corresponding Author) \\ English Language Institute \\ King Abdul-Aziz University, Jeddah, Saudi Arabia \\ E-mail: srshah@kau.edu.sa
}

Received: November 21, 2017 Accepted: December 5, 2017 Published: December 6, 2017

doi:10.5296/jsel.v6i1.12243 URL: https://doi.org/10.5296/jsel.v6i1.12243

\begin{abstract}
This study aims to explore the functions of code switching of English-Arabic speakers in a computer-based online communication. Its goal is to understand whether code switching on the internet has the same functions as face-to-face interaction in real time situation. In addition, it aims to highlight the different conversational characteristics of code switching in a virtual environment, such as online chat. Adopting a Conversational Analysis (CA) approach, the data were collected from online Paltalk chatrooms, specifically "BnatKSA". The six participants, three males and three females were proficient in English and Arabic languages. Using bidirectional English-Arabic code switching, the six participants frequently chatted online for two hours a day over a period of one month. The findings indicate a wide range of functions of code switching on the internet. Some of these functions are unique and context specific, which can be considered a contribution to the body of knowledge. The findings suggest that the range of code switching functions online is broader and more meaningful than face-to-face communication in real time situation.
\end{abstract}

Keywords: Code switching, conversational analysis, Computer-mediated communication, Saudi context 


\section{Introduction}

Over the past four decades, developments such as the expansion of educational provision to various levels of society, massive population shifts through migration, and technological advances in mass communication have served to accentuate our sense of a visibly and audibly multilingual modern world. These developments have resulted in the creation of new social reality in the form of social media networking sites, such as Twitter, Facebook, Linkedin etc., which have formed a digital "contact zone" for millions of people across the globe (Canagajarah 2013, p. 30).

The internet connects diverse communities globally, with English as the dominant language of communication. As there is an exponential growth in the number of internet users from different languages and cultures, various social media networking sites have emerged to connect them through online communication for different purposes. Although English is primarily used as a medium of communication virtually, such as in online chat and e-mails, there are other forums for regional and local communication where normally languages other than English are used. On these forums, people often mix English language with their regional languages for effective communication; however, this results in code switching of different types. The research shows that this phenomenon has been largely ignored in sociolinguistics studies of computer-mediated communication (Siebenhaar, 2006), therefore, the current study focuses on this issue in Saudi Arabian context.

One of the central issues in bilingualism research is code-switching, which is the alternative use by bilinguals of two or more languages in the same conversation. Under this general term, different forms of bilingual behaviors are subsumed. Sometimes switching occurs between the turns of different speakers in the conversation, sometimes between utterances within a single turn, and sometimes even within a single utterance (Hudson, 1980). However, in today's technological era, the question arises if code-switching on the internet occurs in the same way as face-to-face communication. It appears as there is no sufficient evidence in the Saudi context which could show the different functions of code switching in online communication, therefore, the current study examines the bilingual world on the internet and aims to answer the following research questions to fill that research gap.

1. To what extent does code-switching on the internet have the same functions as face-to-face interaction?

2. What are the characteristics and functions of code switching in online communication of English-Arabic speakers in the Saudi context?

\section{Literature Review}

\subsection{Definitions}

Code switching is "the mixing of two or more languages in discourse" (Poplack 2015, p. 918). Scholars consider it as a linguistic behavior found in a bilingual speech (Grosjean 1982; Gumperz \& Hernández Chavez 1972; Sánchez 1983). It has a variety of motives for 
bilinguals that include contextual triggers, discursive function or identity formation (Lavender, 2017). There are two major forms of code switching; emblematic and spontaneous. Emblematic switching refers to fixed phrases of greeting or parting and discourse markers such as: oye, fijate que, you know, pero (cited in Lavender, Grosjean 1982). Spontaneous code switching involves "two (or more) languages... spontaneously brought to bear in a single utterance with no change in interlocutor, situation, or even topic, i.e. with no external trigger" (Popalck 2015, p. 918).

\subsection{The Functions of Code Switching}

A plethora of research underlines the functions of code switching in verbal interaction or face-to-face communication in different contexts (e.g. Gumperz, 1982; Myers-Scotton, 2006; Hymes, 1974; Auer, 1988; Wei, 2005; Lavender, 2017). Auer (1988) considers a conversation analytic approach to code switching that has many functions of under the discourse related to the code switching of Italian people who migrated to Germany.

Gumperz (1982) cites various discourse functions of code switching in a conversational setting. Firstly, it is used to report a speech or quote someone's words in order to convey the exact message of the original speaker. Secondly, code switching is used as fillers and interjections. Thirdly, it can be a tool to re-emphasize or re-iterate what has already been stated. Fourthly, it can function to qualify a speaker's message through introducing a topic and adding comments. Finally, code switching can be used to examine the understand the involvement of the speaker in a message and mark 'We' vs 'They' distinction in a speech (cited in Lavender, 2017). Gumperz (1982) states:

The tendency is for the ethnically specific, minority language to be regarded as the 'wecode' and become associated with in-group and informal activities, and for the majority language to serve as the 'they-code' associated with the more formal, stiffer and less personal out-group relations (Gumperz 1982: 66).

Grosjean (1982) cites various reasons for code switching in a conversational context. Code switching is to:

- Fill a linguistic need for lexical item, set phrase, discourse marker, or sentence filler

- Continue the last language used (triggering)

- Quote someone

- Specify addressee

- Qualify message: amplify or emphasize ('topper' in argument)

- Specify speaker involvement (personalize message)

- Mark and emphasize group identity (solidarity)

- Convey confidentiality, anger, annoyance

- Exclude someone from conversation 
- Change role of speaker: raise status, add authority, show expertise (cited in Lavender, 2017, p. 24).

Conversation analysts have suggested that code switching may serve to enhance turn selection, or soften refusals; it functions as a discourse strategy; as a contextualization cue (Tay, 1989). However, it depends on the topic and context of conversation as a switch likely to occur when the topic of conversation turns to aspects of culture associated with that language (Eid, 1993). Auer (1995) lists eight different contexts in which code switching are most likely to occurs:

- Reported speech.

- Change of participant constellation, particularly addressee selection.

- Parentheses or side-comments.

- Reiteration, that is, quasi-translation into the other language, for purposes of emphasis, clarification, attracting attention, etc.

- Change of activity type, also called "mode shift" or "role shift."

- Topic shift.

- Puns, language play, shift of "key."

- Topicalization, topic/comment structure. (120)

In addition, empirical studies have examined how switches in a language variety serve communication purpose in a particular situation, which explain speaker identities, or background relevant to the ongoing discussion (Tay, 1989). Furthermore, code witching serves as a conversational function, for instance, it facilitates a participant's participation in discussion, helps with topic management and the structure of narratives (Auer, 1999).

\subsection{Code Switching on the Internet}

Recent technological developments have attracted internet users to use various social networking sites as a means of communication with people from other countries and cultures. Due to an overwhelming number of internet users with different languages, users of these social networking sites often rely on code switching to facilitate their communication. boyd [sic] and Ellison (2008) state that social networking sites are "web-based services that allow individuals to (1) construct a public or semi-public profile within a bounded system, (2) articulate a list of other users with whom they share a connection, and (3) view and traverse their list of connections and those made by others within the system" (p. 210).

As stated already, the most recent development is the internet that facilitates interactions. These interactions are Computer-mediated discourses (CMD) that take place when human beings interact with one another by transmitting messages via networked computers (Herring, 2002). While communicating online, the language of internet users is plainly in a state of transition. Wallace (1999) believes that internet participants usually gain a false impression of each other during interaction, which is mainly due to the old set of tools that people use. 


\section{MInstitute ${ }_{\text {Mnk }}^{\text {Macrothink }}$}

Moreover, greater predictability, reliability, familiarity and the language use are factors that affect all internet situations. These factors have been considered crucial in solving the problem of an electronically constrained communication medium in various idiosyncratic ways (Crystal, 2006), which lead to a variety of code switching online.

Researchers have highlighted the importance of code switching on social media sites. For instance, Siebenhaar (2006) believes that code switching on the internet is the analysis of turn-taking in Computer Mediated Communication (CMC) as a single message or chat may contain two or more conversational moves which are physically, but not functionally adjacent.

Choy (2011) investigated the occurrences of code-switching in asynchronous CMC between bilingual university students via social networking website by taking a functional approach in examining the various functions and reasons for codeswitching. Fong's Findings suggest that code switching can take place in online interaction primarily to serve referential, expressive and metalinguistic functions.

Through functional approach, Setianingsih (2015) examined the functions of code switching in asynchronous CMC between bilingual university students via Facebook. The results showed that code switching in online communication was mainly to serve expressive, phatic, directive and metalinguistic functions.

The various purposes of code switching are visible CMC that occurs online. On the internet while communicating via various social networking sites, users make use of different short forms of speeches, use specific vocabulary items and expressions that might not be found in everyday verbal interaction. This social media specific use of words and expressions have been criticized by linguists for different reasons. For instance, Crystal (2005) believes that the language people use on the internet such as 'Good to see you' is written as GTCY / G2SY or a message to express 'lots of love' or 'laughing out loud' are up to the recipient to infer the meaning of the message. Crystal states that the internet allows the users to follow, like never before, the rate and reach of language change in vocabulary, grammar, spelling, and pronunciation with the absence of non-segmental phonology (or tone of voice, which emotions attempted, but failed, to express).

Research shows that different use of CMC specific vocabulary and expression can influence the identity of the users. To understand the impact of the internet communication on the users, Lam (2004) found that Chinese/English chat rooms enabled the users to use English language to create social and ethnic identifications with other young people of Chinese origin in different parts of the world. Similarly, Herring (2002) established that CMC allowed multiple participants to communicate simultaneously in ways that are difficult, if not impossible to achieve in other media sources or devices, which enabled them to develop new identities. In the same direction, Al. Said and Zohry (2002) in Egyptian context ascertained that the internet is not only a boon to English, but potentially to many other languages as well; it is a vehicle for dialects and languages to flourish and improve their self-perceptions. 


\subsection{The Nature of Chatting on the Internet}

Chatgroups trigger continuous discussions on various topics, organized in 'chatrooms' on social media sites, in which users or participants interested in the topics participate. Crystal (2006) categorizes this interaction into two situations depending on whether it takes place in real time (synchronous) or in postponed time (asynchronous). In a synchronous situation, which is the focus of this study, a user enters a chat room and joins an ongoing conversation in real time, sending named contributions which are interested into a permanently scroll-ling screen along with the contributions from other participants. Paltalk is an example of one of the main systems available to users, consisting of thousands of chat rooms dealing with different topics. Although most people enter just one room at a time, there is nothing to stop them opening more than one chat window and engaging into two or more conversations simultaneously, if they have the requisite cognitive and linguistic skills.

In $\mathrm{CMC}$, the term 'Netspeak' is frequently used which is an alternative to 'Netlish', 'Weblish', 'internet language', 'cyberspeak', 'electronic discourse', 'electronic language', 'interactive written discourse', 'computer-mediated communication', and other more cumbersome locations. 'Netspeak', as a term, being popular currency following the Orwellian introduction of Newspeak and Oldspeak in 1984. Later it developed into Doublespeak and Seaspeak and media labels, such as Royalspeak and Blairspeak. It is a broader term than Webspeak. As a name, Netspeak is succinct and functional enough, if we remember that 'speak' here involves writing as well as talking, and that any 'speak' suffix also has a receptive element, including 'listening and reading' (Crystal, 2006).

What makes Netspeak so interesting as a form of communication, is the way it relies on characteristics belonging to both sides of the speech/writing divide. However, there are several major differences between Netspeak and face-to-face conversation. One of them is the formal properties of the medium, properties that are so basic that it becomes extremely difficult for people to live up to the recommendation that they should 'write as they talk'. A key among these properties is the domain of prosody and paralanguage, phonological terms which capture the notion 'it ain't what you say but the way you say it', as expressed through vocal variations in pitch (intonation), loudness (stress), speed, rhythm, pause, and tone of voice (Crystal, 2006).

In more traditional writings, there have been somewhat desperate efforts to replace it in the form of an exaggerated use of spelling and punctuation, and the use of capitals, spacing, and special symbols for emphasis. For example, repeated letters in English or Arabic

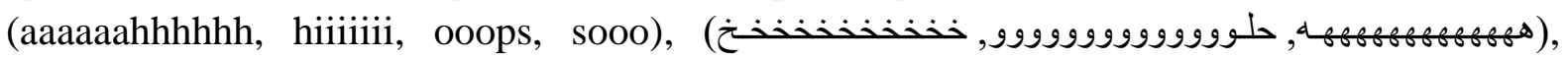
repeated punctuation marks (no more !!!, whohe????), and the following range of emphatic conversations:

all capitals for 'shouting':

spacing for 'loud and clear':

\section{SAID NO}

W H Y, N O T, w h y n o t

On social networking sites, there are letters and keys which allow people to textually express their emotions, often with the addition of synthesized sounds and visual effects. There are 
emoticons that allow users to express happiness, jokes, sympathy, good mood, sadness, boredom, delight, and amusement, etc. These emoticons can only be disambiguated by referring to the verbal context in the communication as the purpose is to make communication easy to understand. This communicative facilitation can also be achieved through features of spoken language, such as mm, mhm, uh-huh, yeah...etc.

Although emotions and feelings are expressed in chatgroups or social networking sites, people often hide their identities. Individuals often use nicknames (nicks), which may be assumed original names, a fantasy description (topdude, sexstar, livelover, lastcry), a pseudonym, a social role (rockman, elfslayer, krendeizar), or countries and famous places. The lexical structure and character of the names themselves is an important feature of Netspeak; but there are other consequences for the type of language used. For instance, operating behind a false persona seems to make people less inhibited: they may feel emboldened to talk more and in different ways from their real world linguistic repertoire. They also expect to receive messages from others who are likewise less inhibited and prepared for negative outcomes. There are obviously inherent risks in talking to an unknown person that can lead to harassment, insult, abuses and aggressive language. However, questions about identity of a kind would be almost unnecessary in face-to-face settings. Certain kinds of information are asked for and given, notably about like Asl (age, sex, and location ), or Morf (male or female).

Multiple and often conflicting notions of truth therefore co-exist in online or virtual situations, ranging from outright lying through mutually aware pretence to playful trickery. As Wallace (1999) refers to the absence of prosodic and kinesics clues in Netspeak allowing the speakers to easily get away with a lie, live with their deceptive identity and harm others while interacting on social networking sites. This practice of hiding identity is one of the attractions for users to operate with a nickname and interact with people from different cultures.

The purpose of chatting online is an intriguing topic. People often seem to post messages not intending real communication, but to demonstrate their electronic presence to other members of a group or to use their medium to help themselves think something different. An extreme situation is found in many chatgroups when different topics trigger discussions but lead to no conclusion or no subject matter that could ever be considered irrelevant.

\subsection{Multilingualism and Social Networking Sites}

The whole business of 'multilingualism' on the internet can be a tricky one, as Leppänen and Peuronen (2012) state, "multilingualism on the internet can refer to the practices of multilingual internet users and the ways in which they draw on and use resources provided by more languages than one in their CMC" (p. 385). They address the issue of language choice as a semiotic strategy that can be used by participants to "distinguish themselves and to create voices of their own in a multilingual online setting" (p. 390). These language choices can shape an individual identity and the notion of community.

The social function of much internet communication has been a major theme of the literature 
in recent years, especially with reference to the concept of a virtual community (Crystal, 2006). While in principle much has been said of its ability to transcend the limitations of physical environments, cultural differences, and time zones, however, it allows people from anywhere to communicate with people anywhere else and discuss topics which might be more restricted and parochial in real time situations. Foster (1997) considers this kind of communication a means to serving individuals and communities and not mass audiences. Rheingold (1993) describes it as an 'ecosystem' of subcultures.

This section of the paper has reviewed literature on the definition of code switching and the notion is used for various purposes by internet users in different contexts around the world. The concise review of literature also shows the functions and nature of internet code switching, which indicates a lack of research on this topic in the Saudi context when Arab speakers proficient in English use code switching on various social media forums, chat groups or networking sites. This study aims to fill that research gap and contribute to the body of knowledge.

\section{Research Design}

This study adopts a Conversation Analysis (CA) approach to bilingual code-switching. This framework was developed against the background of an overwhelming tendency in bilingualism research to explain code-switching by attributing specific meanings to switches and assuming speakers' intended meanings (Wei, 2005). The CA approach avoids imposing analyst-oriented classificatory frameworks and attempts; rather, it reveals the underlying procedural apparatus by which participants themselves arrive at local interpretations of the language choice.

In contrast to other theories of bilingual code-switching, the CA approach dispenses with motivational speculation in favor of an interpretative approach based on detailed, turn-by-turn analysis of language choices/uses. It is not about what bilingual conversationalists may do, or what they usually do, or even about what they might see as the appropriate thing to do. Instead, it is about how the meaning of code-switching is constructed in interaction (Wei, 2005).

Applying the CA approach, this study aims to analyze and examine the functions of codeswitching in a natural conversation, since the data are transferred from the "KSAIIIBnatKSAIIIKSA" chat room. The study provides a rich description of the conversation between three males and three females Arabic/English speakers.

\subsection{Data Collection and Analysis}

The data were gathered from conversations that happened in paltalk chatrooms specifically a chatroom named "KSAIIIBnatKSAIIIKSA". The data were consisted of two hours chat per day for a period one month, which were copied from the chatting room to the MS word file and divided into various categories according to their functions. The total conversations were 30 . 


\section{Macrothink}

The six participants, three males and three females who were Arabic/English speakers were not known to the researchers. Therefore, their ages, personal details and demographic details were not considered. From the data, we recognized that the switches were bidirectional in their online chats. In the analysis, the original data are shown in italic while the English translation is given in the standard form. In addition, the numbering of the data is stated according to the number of lines in each conversation.

\subsubsection{Functions as Face to Face Code Switching}

\subsubsection{Repair}

1 Me...Me: what else do u like what is ur favorite hobby

2 3aZoZ: i like to play sports

3 3aZoZ: and read

4 3aZoZ: what about u?

5 Me...Me: i like to exercise

6 3aZoZ: thats good.. u must have a good body

7 Me...Me: $i$ am trying bcuz $i$ like eating

8 3aZoZ: what do u look like?

9 Me...Me: all kinds of macaroni, steaks, soups, salads, chocolate

10 3aZoZ: nice

$11 M e . . M e:$ u didn't tell me what do u like in food

12 3aZoZ: pizza, burgers, steaks, alot of things

13 Me...Me: and $u$ are bold right

14 3aZoZ: bold?

15 Me...Me: sorry i mean rashik sah (elegant right)

16 3aZoZ: laa (no)

17 3aZoZ: i have hair

18 Me...Me: ur funny

In the above extract, the conversation between a male and a female started in English discussing their hobbies and the kind of food they like. In line $12,3 a Z o Z$ is answering $M e . . . M e^{\prime}$ s question about the food he likes (pizza, burgers, steaks, a lot of things) to eat, then $M e . . . M e$ in line 13 said ' $u$ are bold right' but $3 a Z o Z$ didn't understand her meaning, since they were talking about fitness and food and asked (bold?) in line 14 . In line $15 \mathrm{Me} . . \mathrm{Me}$ repaired her wording by saying in English (sorry I mean) then switching to Arabic (rashik sah). Hence, here the function of the switch is to repair by another participant who 


\section{Macrothink

recognized the mistake or the overlapping utterance.

\subsubsection{Topic Change}

$1 \quad$ Che777: are u saudi?

2 rosita321: yes

3 Che777: actually, this is my first time to be in Saudi, Riyadh, i am from

4 Jordan, studied in england

5 Che777: tell me more about saudi girls

6 Che777: what they like waht they dont like

7 Che777: I mean in general

8 Che777: how can I flirt with them?

9 rosita321: $\mathrm{km}$ ga3at in England? (How much did you stay in England?)

11 Che777: I studied there then worked for couple of years

12 Che777: I spent 3 years there

13 rosita321: and how was it? did u enjoy staying there?

14 Che777: nice actually

15 Che777: It was good for me as a single

16 Che777: I had a good time

17 rosita321: ma adri 3an alriyadh $i$ didnt visit it (I don't now Riyadh, I didn't visit it)

18 Che777: gareeb, ma3 anha al 3asmah (strange, it's the capital)

19 Che777: kalmkoom $7 l o$ (your speech is nice)

20 Che777: I liked it ma adreee so much (I liked it I don't know why)

21 rosita321: kalam meen jeddah, Riyadh (Who's speech Jeddah or Riyadh)

22 Che777: I meant saudi girls in general, But I prefer the Jeddah accent

23 Che777: hope you have it

24 rosita321: 3ndi aljidawi (I have Jeddah's accent)

25 Che777: 7looo kteeer (very nice)

In the above extract, the communication is between a male and a female where they started the conversation in English, first, Che 777 the male, in line 1 he asked if rosita321 is from Saudi Arabia, then in line 3 he talked about himself (his origin, where he studied). In addition, he said that this was the first time for him to be in Saudi Arabia and he wanted to 
know more about Saudi girls in line 4, 5, 6. Once he asked (how can I flirt with them ?) in line 7, rosita321 decided to change the topic, to talk about herself, rather than about Saudi girls, so she switched to Arabic and asked ( $\mathrm{km}$ ga3at in England?) in line 8. Then, Che777 answered her question and they completed the conversation in English talking about England until line 15 where rosita 321 switched again to Arabic when saying that she didn't visit Riyadh (ma adri 3an alriyadh $i$ didnt visit it). When rosita321 switched to the topic of talking about Riyadh, most of the conversation was completed in Arabic shown in lines 16, 17, 19, $22,23$.

In the later switch, we can see that the function of topic change refers to talking about two different societies. The underlying assumption is that speakers recognize a basic congruence between certain kinds of topics and codes, and that this congruence ultimately rests on the meanings or values of the languages in the repertoire. Speakers, therefore, switch to the code they consider more appropriate for a given topic (Alfonzetti, 1992).

\subsubsection{Story Telling}

1 Me....Me: Aktar min ai shai a7s ini a7taj atkalam 3n ashia'a shuftaha bitih9al

2 fi alghrfa. My dear friends: As many of you have known I have been at my

3 moms home in Damam as she has battled liver cancer. Sadly she has lost the

4 battle and is now at home with her maker. so Ana sa3ida lima3rifiat Cindy

5 and MMPmin yaoum ma itfatahat al ghrfa wa a3raf gadiaish wagt, majhood

6 w 7 ub wada3o 3shan y3milo hatha almakan muree7 llderdesha. Bas katteer

7 min alnaas ye9rif al nather 3an 3alm al mehadethah bisabab al ashia'a al

8 sayia'ailiyshofoha wi ysma3oha. The don't see the over 300 e-mails I received

9 during this period. The don't know the calls I have gotten from chatters

10 wishing me well and offering support.

Translation:

(Me...Me: More then anything, I need to talk about some of the things I have seen posted about incidents in the room. My dear friends, as many of you know I have been at my moms home in Dammam as she has battled liver cancer. Sadly, she has lost the battle and is now no more with us. So many people anyway dismiss chatters and the "community" we have, but it's because of the negative things they see and hear. They don't see the over 300 e-mails I received during this period. They don't know the calls I have got from chatters wishing me well and offering support.)

Here in extract 3, the conversation started in line 1 in Arabic by $\mathrm{Me}$...Me, a female, talking about what she wanted to say about the chatroom that she belongs to but before she talked about the chatroom, she narrated a painful story that happened to her in line 2 . Once she began presenting the story, she switched to English. After finishing the story in line 4, she 
switched to Arabic again to express her feelings about how helpful her friends were in trying to make the chatroom warm and pleasant but some people do not appreciate the chatting community. Then, in line $8 M e . . . M e$ switched to English reporting the number of e-mails and calls she received from chatters.

The function of story-telling can be seen in the chat which is mainly in English. Codeswitching often occurs in utterances to serve as story prefaces, in which the would-be teller projects a forthcoming story, thus trying to ensure himself a stretch of uninterrupted talk (Alfonzetti, 1992).

\subsubsection{To Quote}

1 misundersto0oOod: $u$ study?

2 reema: yes

3 reema: business administration

4 misundersto0o0od: I see

5 misunderstoOoOod: where?

6 reema: Dubai

7 misundersto0o0od: 2nd year, right?

8 misundersto0o0od: or third?

9 reema: first

10 misundersto0o0od: ok i finished my questions

11 misundersto0oOod: thnx

12 reema: so

13 misundersto0o0od: good luck

14 misundersto0o0od: keep going

15 reema: why do u say xala9 ma 3indi asiila (why do you say "finished my questions)

16 misundersto0oOod: cause i have no more

18 misundersto0o0od: just like that

19 reema: ya3ni akked $U$ have no more (sure you have no more)

20 misundersto0o0od: ya cause befor i make friendship ask these questions

In the above extract, misunderstoOoOod, the male, started the conversation in English and wanted to know reema's academic background from lines 1-9. Then, in line 10 misundersto0oOod said "ok I finished my questions". reema in line 15 switched to Arabic (why do u say xala9 ma 3indi asiila) to quote his saying. In this regard, Myers-Scotton (1993) 


\section{Macrothink}

states that occasional switching in quotations may not be due to the purpose of preserving the original language. In case of the abovementioned chat, code switching happened in the whole quote and not occasionally. To underline misundersto0o0od wording (ok I finished my questions), as he did not have any questions to ask, reema switched to Arabic again (ya3ni akked $U$ have no more) in line 19.

\subsubsection{New Functions of Code Switching on the Internet}

\subsubsection{To Get Information}

1 rosita321: I watch movies when I don't have something to do.

2 Che777: I like watching movies in the cinema

3 rosita321: i7na ma 3andana cinema

4 Che777: no fee (no there is)

5 Che777: we have one here

6 Che777: I am watching movies in the cinema here

7 Che777: it is not that big

8 Che777: but it is a good cinema

9 Che777: 300 people visit it every week

10 rosita321: min jid, fain (really where?)

11 Che777: in Riyadh, it is not official one

12 Che777: it is inside a compound, I live in

13 rosita321: awlaad and banat (boys and girls)

14 Che777: mixed

15 Che777: both

16 Che777: well come here and I will give you a ticket

17 Che777: it is an american compond

18 Che777: that is why

19 rosita321: fi aflam 3arabia (Are there Arabic films)

20 Che777: actually you can ask for any movie

21 rosita321: mrrrrrrrrrrrrrrrrrra helloooooooooooooooooo (very nice)

22 Che777: anyone you wish to watch they will play it

23 Che777: any time 
24 Che777: any movie

25 rosita321: tib ana daheeeeeeeeeeeen come hhhhhhhhhhhhhhhhh, buy me a ticket (ok, I am coming now buy me a ticket)

The above extract is an interesting conversation because it shows how to get information when the aim is to know about an issue. From line 1, where rosita321 started in English, it is clear that she liked watching movies. To express her displeasure about not having cinema in Saudi Arabia, she switched to Arabic in line 3 (ihna ma 3andana cinema). To emphasize that there is a cinema in Saudi Arabia Che 777 in line 4 switched to Arabic when he said (no fee). Then, from rosita321's wordings in lines 10 (min jid, fain), line 13 (awlaad and banat), and line 19 ( i aflam 3arabia), it is noticeable how she switched to Arabic while Che777 was conversing in English to get information about something she is interested.

\subsubsection{To Indicate the Opposite}

1 reema: kaif al jaw 3indakm cold (how is the weather there)

2 misunderstoOoOod: very cold

3 misundersto0o0od: urs?

4 reema: fi almorning and laial cold but afternnon 7ar (in the morning and

$$
\text { night cold but in the afternoon hot) }
$$

5 misundersto0o0od: rainy?

6 reema: no rain in dubai mafi matter fi dubai (there is no rain in Dubai)

7 misunderstoOoOod: poor

8 misundersto0o0od: it was rainy yesterday

In the above extract, reema started the conversation started in Arabic talking about the weather where she asked misundersto0oOod in line 1 (kaif al jaw hindakm cold). From the beginning of the conversation misundersto0o0od mentioned that he was staying in Philadelphia. Then, in 4 reema mentioned the climate in Dubai using opposites (fi almorning and laial cold but afternnon 7ar). Hence, to indicate opposites is recognized as a new function for code switching. In the conversation, we have another function which is repetition, to stress the idea of not having rain in Dubai as shown in line 6 (no rain in dubai mafi matter fi dubai).

\subsubsection{To Repeat the Information}

1 3aZoZ: what is your best feature?

2 Me...Me: ish ga9dak what do u meen (what do you mean)

3 3aZoZ: wsh a7san shy feek? (what is your best quality)

4 3aZoZ: a7sn meezah (best characteristic) 


\section{Ml Macrothink}

5 Me...Me: my style is always in a change

6 3aZoZ: w9fee lee shklk (describe your shape)

7 Me...Me: i am

8 3aZoZ: you are what?

9 Me...Me: not that beautiful, wa7sha, na7ifa, fat, tawila, short, I hav long

hair, but mafi sha3ar! (not that beautiful, ugly, thin, fat, tall, short, I have long hair, but no hair)

In the above extract, the same functions that appeared in extract 6 is noticeable. Starting in English, $3 a \mathrm{ZoZ}$ asked in line 1 (what is your best feature?) but Me...Me didn't understand his question so she switched to Arabic to show that she didn't comprehend the meaning and switched to English again to repeat the misunderstanding as shown in line 2 (ish ga9dak what do $u$ meen). To highlight the meaning, $3 a \mathrm{ZoZ}$ (the male) switched to Arabic in lines 3 (wsh a7san shy feek?), and 4 (a7sn meezah). The code-switch for indicating opposites is shown in lines 9, and 10 (not that beautiful, wa7sha, na7ifa, fat, tawila, short, I hav long hair, but mafi sha3ar!).

\subsubsection{To Express Sad Feelings}

1 Me...Me: why ar u sad today

2 3aZoZ: i don't know

3 Me...Me: what is bothering $u$

4 Me...Me: $i$ wont tell anyone

5 3aZoZ: ok

6 Me...Me: so?

7 Me...Me: or u don't want to tell me

8 3aZoZ: it's not like that

9 Me...Me: why don't u do somthing $u$ like to forget

10 3aZoZ: ya

11 3aZoZ: listinin to rock muzic

$12 \mathrm{Me} . . . M e$ : walking sometimes helps

13 3aZoZ: ya

14 3aZoZ: u know somethin

$153 a Z o Z:$ الحياة قاسية (life is tough)

16 3aZoZ: المطلوب انتا نكون داعما في القعة (we better stay on top of it) 
17 Me...Me: $u$ ar so depressed

18 Me...Me: what happened

19 3aZoZ: هذي الحقيقة

(this is the truth)

20 3aZoZ: this is life

21 Me...Me: try to think in a way to solve the problem

22 3aZoZ: loool (laugh out loud)

23 3aZoZ: بغني افكرفي الموت (you have to die then)

$24 \mathrm{Me}$...Me: and remember that allah is always there

25 3aZoZ: الحمد لله (thanks to Allah)

$26 \mathrm{Me}$...Me: if you talked to him he will listen to you

27 3aZoZ: i know

28 3aZoZ: but idon't like to talk about this it's personal between me n him

29 Me...Me: no problem

30 Me...Me: but always remember him

40 3aZoZ: i do

41 3aZoZ: sweety listin to me

42 3aZoZ: هنا بشر

(we are humans)

43 3aZoZ: و البشر معقد (humans are complicated)

44 3aZoZ: ونحنا بنعقد حياتنا (we are complicating ourselves)

45 3aZoZ: i reali don't know why i talk about this

46 3aZoZ: just forget about it

47 Me...Me: ok lets change the topic

48 3aZoZ: ok

49 Me...Me: did u see the new channel

In different situations, people sometime code-switch to express some kind of feelings. Since $3 a Z o Z$ and $M e . . . M e$ became friends, Me...Me knew that there wass something bothering $3 \mathrm{aZoZ}$ which was visible in his chat, so she inquired about his sadness. He did not tell her the

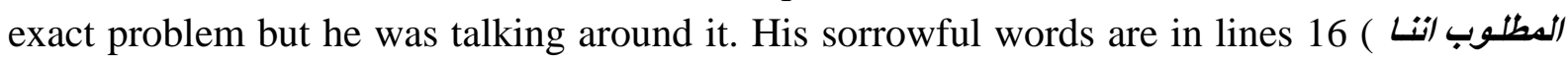

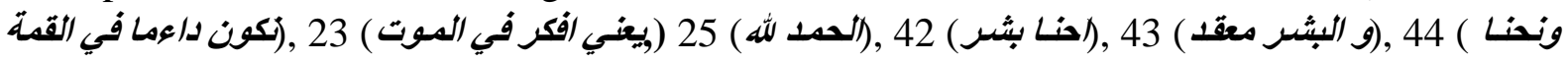
(بنعقد حياتنا $M e . . . M e$ was trying to help him to get out of that mood by going back to God then they 
decided just to change the topic.

\subsubsection{To Express Happiness}

1 rosita 321:Congrats on the new granddaughter Me. That's a beautiful name.

2 What a great way to start off the new year!! A new life and a re-newed life

$3 \quad ! ! ! !$

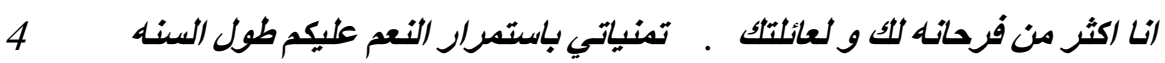

Translation:

What a great way to start off the new year !! A new life and a re-newed life !!!! I am overjoyed for you and your family. May the blessings continue all through the year.

One of the feelings that participants try to show is happiness. In extract 5, rosita 321 is trying to share her friend's happiness. She started chatting in English conveying how nice to start a new year with a new baby. To express her joy more explicitly, she switched to Arabic in line 4 by wishing her good luck for the year ahead.

\subsubsection{To Show Comfort}

1 reema: God Bless you during these next few days, and weeks also. Losing a

2 parent is traumatic. Please know that my thoughts and prayers are with you

3 and yours. Iza a7tajti titkalami m3 a7ad fi ai wakt itzakari ini moujood

4 daimaa fi al ghrfa.

Translation:

reema: God Bless you in the days and weeks to come. Losing a parent is traumatic. Please know that my thoughts and prayers are with you. If you ever need anyone to talk to, please know that I am here.

This is a response to the story reema learned. reema in line 1 started in English to comfort Me...Me. Then in line 3, reema switched to Arabic (. Iza a7tajti titkalami m3 a7ad fi ai wakt itzakari ini moujood daimaa fi al ghrfa) to hold up Me...Me. It can be inferred from this communication that sometimes we code switch when we want to show support to someone and this kind of code switch has a special motive, as Myers-Scotton (1993) pointed out that Participants switch codes due to their personal motivations as codes in bilingual interaction, convey certain social and symbolic meanings. Therefore, these codes have special relationships.

3.1.2.7 To Make the Writing Easier and Faster

1 misundersto0oOod: لبه ما درستي بكلية عفت؟ (Why you didn't study in Effat 
collage)

2 misundersto0oOod: مرف الكلبه هذي مشهورة (I know that it is a famous one)

3 misunderstoOoOod: و بعدين فيها تخصصات ما توجد في الجامعات الثانية (and it has all the specializations that are not there in other universities)

4 misundersto0oOod: زي الهندسة (like engineering)

5 misundersto0o0od: قصدي هندسة للبنات (I mean girls engineering)

6 reema: 3shan ma jat 3al bali wa KAAU is free (I didn't think of it and KAAU is free)

7 misundersto0oOod: صح مجاني (right it is free)

8 misundersto0oOod: و بعدين جامعة الملك عبدالعزيز قوية و مشهورة و لها /حتر/مها

(Another thing is that KAAU is strong, famous, and has its respect)

9 reema : and al shad 3alamia everywhere (the certificate is universal)

10 reema: in what koliah did u study (in what collage do you study)

11 misunderstoOoOod: طب (medicine)

12 misundersto0oOod: سألتاك معترف فيها عالمبا جامعة الملك عبدالعزيز؟ (I asked you is it universal)

13 reema: في اي تخصص

14 misundersto0oOod: ما فبه تخصصص

15 misunderstoOoOod: طب عام

16 reema: it is universal

17 misunderstoOoOod: ليه انتي تتأخرين بالرب؟

18 misunderstoOoOod: احس ردك يجي متأخر

19 reema: ما /عرف الحروف العربية على key board (I don't know how to write Arabic (you specialized in what?)

(no specialization)

(general medicine)

(why are you late in answering)

(I feel that your answer comes late)
20 misunderstoOoOod: خلاص اكتبي بالاتجليزي

21 misunderstoOoOod: بس ردي ببرعة

22 reema: ok

23 reema: so when do u come back from work

24 misunderstoOoOod: الساعة اربع العصر تقربيا (nearly at 4 o'clock)

(ok write in English)

on the board)

(but be quick in answering) 
25 reema: which year

26 misundersto0o0od: الثالثة

(the third year)

27 reema: do u have time to chat

28 misunderstoOoOod: (honestly these 2 days I am free)

29 reema: its exams know

30 misundersto0oOod: بح بس انا علي سلم بيوم الأحد

Sunday)

31 misundersto0o0od: سكلة

(it is easy)

32 misunderstoOoOod: الاختبارات بعد اسبوع

(the exams are after a week)

33 reema: what is slm

34 misundersto0o0od: تعرفين اسبوع الاعدادي (Do you now the preparation week)

35 misundersto0oOod: الاعداد العام هو اختبارات المواد الإسلامبية البسيطة و نسيها سلم اختصار لإسلاميات (the general preparation is exams of the easy

lessons like Islam lessons)

In the above extract, misunderstoOoOod started the conversation in Arabic with reema about reema's colleagues in Jeddah. misundersto0o0od inquired about their specializations and background. In line 6, reema typed English alphabets to convey a message in Arabic and code switched too (3shan ma jat 3al bali wa KAAU is free). This happened in line 9 (and al shad 3alamia everywhere) and line 10 ( in what koliah did u study) as well. All these sentences indicate reema's difficulty to type or chat in Arabic. In lines (17, 18) (لوبه انتـي تتأخرين بالرد؟) (هس ردك يجسي متسأخر), misundersto0oOod asked reema the reason for being slow in writing/typing? She responded that she was not used to type Arabic and it was easier for her to chat in English. This turned their conversation into English. This is an important function of code switching on the internet as some users chat in Arabic and others are comfortable typing in English that will lead to code-switching.

\section{Discussion}

Studies reviewed in this paper have shown that code-switching is a form of communication that is neither random nor haphazard; rather, it is adjusted by the users to their communicative benefit in a consistent manner. As sociolinguists have drawn attention to the functions of code switching in face-to-face communication, this study is an example of Arabic and English speakers' code switching in a virtual environment. The findings have aimed to answer the two key research questions:

1. To what extent does code-switching on the internet have the same functions as face-to-face 
interaction?

2. What are the characteristics and functions of code switching in online communication of English-Arabic speakers in the Saudi context?

This study has focused on examining examples of code switching in online chatting on the internet between in the Saudi context. The findings show various functions of code switching on the internet like topic management, speech repair, story-telling, repetition of information, and quotation that are similar to the functions of face-to-face communication. In addition, however, this study found new kinds of functions like indicating opposite views such as getting information about something interesting that requires a code switch from English to Arabic. There are also functions of expressing feelings such as sadness, happiness, and expressing relief and satisfaction, which are the unique characteristics of this findings. It is believed that there is a special relationship between the users that is built up through code switching on the internet. Moreover, it can also be inferred that feelings, sentiments and emotions are best expressed in the speakers' L1, rather than in the target language, i.e. English. This is similar to what McKenna, Green, Gleason and Herring (2002) stated that internet users often develop intimate relationships that are close, meaningful, and long lasting. These virtual relationships are usually brought into the real world by meeting, talking, and connecting with each other in different ways that indicate the crucial role of selfperception and social identity in the process of building social and virtual bonds.

The most overarching functions of online code switching that this study found are topic change and seeking information. This may be due to the nature and reason of online chatting where people converse on the internet to exchange new topics and to get new information and details about things and people they do not know or are interested to know about. This shows that internet users often discuss a wide range of topics on social media. Another subject that we recognized from the data is that girls code switch more than boys; however, the data do not explicitly indicate the reasons for their frequent code switching from English to Arabic. With respect to gender and code switching in different languages, researchers may find it an interesting research endeavor in the future.

It is noticeable in the participants' chat that they can easily switch from formal to informal language use without knowing each other, a phenomenon may not be found in face-to-face interaction. The formal language use from the data seemed to be in Arabic and the informal language use was mainly in English. For instance, when Che777 asked an informal question ' how can I flirt with them?', rosita321 decided to switch to formal language and said 'km ga3at in England? The use of informal expressions in English might be the influence of electronic and social media as young people often switch to informality on Twitter, Facebook etc. Moreover, this may show their lack of formal use of English language while communicating online.

The findings also make a strong point that code switching on the internet can be done in two major ways, either by typing Arabic-English or English-Arabic using English letters or alphabets. The participants' extracts have abundantly shown these examples. This is a feature that makes a difference between code switching in face-to-face communication and code 
switching on the internet. On the internet, the users need to speak/ write; however, in face-toface communication only verbal communication is adequate. Moreover, face-to-face communication relies on body language and facial expressions, which is a completely missing feature from online chat. Chatters who are used to typing in Arabic would write/type using Arabic alphabets, but those who are used to speak Arabic and are not used to write Arabic would prefer to use English letters. In both cases, the purpose is to make the communication easier and faster.

\section{Conclusion}

This study has explored the uses and functions of code switching by Arabic and English speakers interacting in a virtual world. The conversational analysis of six participants have indicated various functions and forms that chatters usually apply while communicating online in a chatroom. The findings show the significance of code switching in relation to facilitating communication between the speakers of Arabic and English languages. The findings suggest that NetSpeak as a new variety of internet language will continue to develop and encompass new properties of language which will be utilized by the users for their benefits. As a new linguistic medium, Netspeak will undoubtedly grow in its sociolinguistics and stylistic complexity to be comparable to that already known traditional speech and writing. In a nutshell, based on the findings on this study, we can agree with Rheingold (1993), the creator of various web languages projects that the future of the internet lies in more multilingualism and cross-cultural exploration and understanding than we have seen so far.

\section{References}

Alfonzetti, G. (1992). The conversational dimension in code-switching between Italian and dialect in Sicily. Milano: Franco Angeli.

Auer, J. C. P. (1998). Code-Switching in conversation; language, interaction and identity, New York, Routledge.

Auer, J. C. P. (1995). The pragmatics of code-switching: a sequential approach. In One speaker, two languages. Cambridge University Press.

Bassiouney, R. (2006). Functions of code-switching in Egypt. Brill Leiden, Boston.

boyd, d. m., \& Ellison, N, B. (2008). Social Network Sites: Definition, History, and Scholarship. Journal of Computer-Mediated Communication, 13, 210-230.

Canagarajah, S. (2013). Translingual Practice: Global Englishes and Cosmopolitan Relations. Routledge.

Choy, W. F. (2011). Functions and reasons for code-switching on Facebook by UTAREnglish-Mandarin Chinese bilingual undergraduates (Doctoral dissertation, UTAR).

Crystal, D. (2005). The scope of the internet linguistics. Paper given on line to the American 
association for the advancement of science meeting.

Crystal, D. (2006). Language of the internet. Cambridge University Press.

Eid, M. (1993). Directionality in Arabic-English Code-Switching. University Press.

Warschauer, M., Said, G. R. E., \& Zohry, A. G. (2002). Language choice online: Globalization and identity in Egypt. Journal of Computer-Mediated Communication, 7(4), $0-0$.

Foster, D. (1997). Community and identity in the electronic village. Internet culture, 5(3), 23-39.

Grosjean, F. (1982). Life with Two Languages: An Introduction to Bilingualism. Cambridge, Mass: Harvard University Press.

Gumperz, J., \& Hernandez C. (1972). Bilingualism, bidialectalism and classroom interaction. Language in social groups. J. J. Gumperz (ed.). Stanford: Stanford University Press, 311-39.

Herring, S. C. (2002). Computer-mediated discourse. Blackwell, Oxford.

Hudson, R. A. (1980). Sociolinguistics. Cambridge University Press.

Hymes, D. (1974). Foundations in sociolinguistics: an ethnographic approach. Philadelphia, University of Pennsylvania Press.

Lam, W. (2004). Second language socialization in a bilingual chat room: global and local considerations. Language Learning \& Technology, 8(3).

Lavender, A. J. (2017). Code switching, lexical borrowing, and polylanguaging in valencia Spanish: An analysis of data from conversational corpora and Twitter (Doctoral dissertation, State University of New York at Albany).

Leppänen, S., \& Saija, P. (2012). Multilingualism on the Internet. In The Routledge Handbook of Multilingualism (eds. Marilyn Martin-Jones, Adrian Blackledge and Angela Creese), 384-402.

McKenna, K.Y. A., Green, A., \& Gleason, M. (2002). Relationship formation on the internet: What's the big attraction? Journal of Social Issues, 58(1), 9-31. https://doi.org/10.1111/1540-4560.00246

Myers-Scotton, C. (1993). Social motivations for code-switching. Oxford University Press, Oxford.

Myers Scotton, C. (2006). Multiple voices: an introduction to bilingualism. Blackwell, Oxford.

Poplack, S. (2015). Code switching: Linguistics. International Encyclopedia of the Social and Behavioral Sciences, 2nd ed. Vol. 3.

Rheingold, H. (1993). The virtual community: homesteading on the electronic frontier. New York: HarperCollins. 
Sánchez, R. (1983). Chicano discourse. Rowley: Newbury House.

Setianingsih, R. (2015). The functions of using code switching on facebook By EFL learners (Doctoral dissertation, Program Studi Pendidikan Bahasa Inggris FBS UKSW).

Siebenhaar, B. (2006). Code choice and code-switching in Swiss-German internet relay chat room. Journal of Sociolinguistics, 10(4), Blackwell Publishing Ltd.

Tay, M. W .J. (1989). Codeswitching and codemixing as a communicative strategy in multilingual discourse. World Englishes, 8(3), 407-417. Tilburg University press.

Wallace, P. (1999). The psychology of the internet. Cambridge: Cambridge University Press.

Wei, L. (2005). “How can you tell?”: towards a common-sense explanation of conversational code-switching. Journal of Pragmatics, 37(3), 375-389.

\section{Copyright Disclaimer}

Copyright for this article is retained by the author(s), with first publication rights granted to the journal.

This is an open-access article distributed under the terms and conditions of the Creative Commons Attribution license (http://creativecommons.org/licenses/by/3.0/). 